\title{
TEMPERATURA E REGIME DE LUZ NA GERMINAÇÃO DE SEMENTES DE Tabebuia impetiginosa (Martius ex A. P. de Candolle) Standley e T. serratifolia Vahl Nich. - Bignoniaceae ${ }^{1}$
}

\author{
Temperature and light in germination of Tabebuia impetiginosa \\ (Martius ex A. P. de Candolle) Standley and T. serratifolia Vahl Nich. SEEDS - Bignoniaceae
}

\author{
Luciana Magda de Oliveira², Maria Laene Moreira de Carvalho ${ }^{3}$, \\ Tanismare Tatiana de Almeida Silva ${ }^{4}$, Daniela Inês Borges ${ }^{4}$
}

\section{RESUMO}

O teste mais tradicionalmente utilizado para a avaliação da qualidade de lotes de sementes é o teste de germinação. A metodologia do teste de germinação ainda não está bem definida para sementes de Tabebuia impetiginosa (ipê-roxo) e T. serratifolia (ipê-amarelo), uma vez que são encontrados na literatura poucos trabalhos referentes especificamente à definição das condições ideais para a realização do teste nessas espécies. Objetivou-se com este trabalho verificar o efeito de temperatura e luz na germinação de sementes de diferentes lotes de ipê-roxo e ipê-amarelo. Para o ipê-roxo, a seleção das temperaturas foi realizada inicialmente em mesa de termogradiente, com temperaturas variando de $20,9^{\circ} \mathrm{C}$ a $34,4^{\circ} \mathrm{C}$ e, posteriormente, em BODs, com temperaturas de $25^{\circ} \mathrm{C}$, $30^{\circ} \mathrm{C}$ e $35^{\circ} \mathrm{C}$. Para o estudo do efeito da luz na germinação das sementes de ambas as espécies, os tratamentos foram instalados em BODs sob três regimes de luz: luz branca contínua/temperatura de $30^{\circ} \mathrm{C}$, branca alternada com fotoperíodo de 8 horas/temperatura de $20 / 30^{\circ} \mathrm{C}$ e escuro/temperatura de $30^{\circ} \mathrm{C}$. A temperatura de $30^{\circ} \mathrm{C}$ foi adequada para a germinação de sementes de ipê-roxo, independente do ano de colheita ou da qualidade fisiológica dos lotes, enquanto a resposta da germinação em relação ao regime de luz variou conforme o ano de colheita. A condição ideal para realização do teste de germinação em sementes de ipê-amarelo, independente da procedência e do ano de colheita, foi sob luz constante a $30^{\circ} \mathrm{C}$.

Termos para indexação: ipê-amarelo, ipê-roxo, qualidade de sementes.

\begin{abstract}
The most traditionally used test in order to evaluation seed lots quality is the germination test. However, the germination test methodology is not well defined for Tabebuia impetiginosa (ipê-roxo) and T. serratifolia (ipêamarelo) seeds. This is probably due to the little attention that the species received, specifically, about the definition of the ideals conditions for germination of these species. Thus, the objective of this research was to verify the effect of temperature and light on germination of T. impetiginosa and T. serratifolia seeds. The research was performed in a thermo-gradient table with temperature varying from $20,9^{\circ} \mathrm{C}$ to $34,4^{\circ} \mathrm{C}$ and in BODs with temperatures adjusted at $25^{\circ} \mathrm{C}, 30^{\circ} \mathrm{C}$ and $35^{\circ} \mathrm{C}$. To study the effect of light on germination for both species the seeds were incubated in BODs at white light/temperature $30^{\circ} \mathrm{C}$, alternate white with photoperiod 8 hours/temperature $20 / 30^{\circ} \mathrm{C}$ and in the darkness/temperature $30^{\circ} \mathrm{C}$. The temperature of $30^{\circ} \mathrm{C}$ was suitable for the germination of $T$. impetiginosa seeds, irrespective of the year of collection or physiological quality of the batches, while the effect of light on germination varied according to the year of collection. The ideal condition for accomplishment of the germination test in $T$. serratifolia seeds, irrespective of the provenance and year of collection, was under constant light at $30^{\circ} \mathrm{C}$.
\end{abstract}

Index terms: ipê-amarelo, ipê-roxo, seed quality.

(Recebido para publicação em 26 de abril de 2004 e aprovado em 3 de maio de 2005)

INTRODUÇÃO

As espécies do gênero Tabebuia têm sido utilizadas com propósitos madeireiros, de restauração de áreas devastadas, bem como para fins medicinais; mas, apesar da importância dessas espécies no contexto nacional, o alto grau de desmatamento tem levado à diminuição das populações e à destruição das árvores,

1. Parte da tese de doutorado apresentada à Universidade Federal de Lavras/UFLA pelo primeiro autor.

2. Engenheiro Florestal, Dra., Universidade Federal de Lavras/UFLA - Caixa Postal 3037 - 37200-000 - Lavras, MG - lumagda@ufla.br

3. Engenheiro Agrônomo, Dra Profa. - Departamento de Agricultura/UFLA - mlaenemc@ufla.br

4. Engenheiro Agrônomo, Universidade Federal de Lavras/UFLA. 
como das espécies Tabebuia impetiginosa (ipê-roxo) e T. serratifolia (ipê-amarelo). A espécie T. impetiginosa corre perigo de extinção, estando na relação das espécies para conservação genética 'ex situ', no Instituto Florestal de São Paulo (SIQUEIRA \& NOGUEIRA, 1992).

A propagação dessas espécies ocorre, principalmente, por sementes (CARVALHO, 1994), que apresentam variação na qualidade durante o armazenamento. A avaliação da qualidade das sementes é, tradicionalmente, efetuada pelo teste de germinação; no entanto, há uma grande variação entre as metodologias utilizadas nesse teste, o que dificulta a comparação dos resultados. A temperatura utilizada na germinação de sementes de Tabebuia varia de $20{ }^{\circ} \mathrm{C}$ a $35^{\circ} \mathrm{C}$, contínua ou alternada (CUNHA et al., 1992; DIAS et al., 1992; MAEDA \& MATTHES, 1984; MELLO \& EIRA, 1995; PINTO et al., 1986; SALES \& CASTRO, 1994; SALOMÃO \& MUNDIN, 1997). Quanto à luz, o teste de germinação foi efetuado na presença de luz constante (PINTO et al., 1986; SALOMÃO \& MUNDIN, 1997), alternada (CUNHA et al., 1992; SALES \& CASTRO, 1994) ou no escuro (DIAS et al., 1992). Machado (1999) observou que o fotoperíodo de 12 horas, sob substrato sobre papel ou sobre areia e temperatura de $30^{\circ} \mathrm{C}$, favorece a germinação de sementes de ipê-amarelo. Para a realização do teste em sementes de ipê-roxo, Barbosa (1982) recomenda o uso de temperatura de $25^{\circ} \mathrm{C}$ em substrato sobre areia.

Em face do exposto, observam-se a importância e a necessidade de estudos relativos à avaliação da qualidade de sementes do gênero Tabebuia. Objetivouse com este trabalho verificar o efeito de temperatura e luz na germinação de sementes de diferentes lotes de ipê-roxo e ipê-amarelo.

\section{MATERIAL E MÉTODOS}

O trabalho foi desenvolvido no Laboratório de Análises de Sementes, Departamento de Agricultura da Universidade Federal de Lavras (UFLA), em duas etapas. A primeira etapa foi destinada a avaliar o efeito de temperatura em sementes de ipê-roxo, e a segunda, o efeito da luz na promoção da germinação de sementes de ipê-roxo e ipê-amarelo. As sementes foram retiradas da condição de armazenamento em câmara fria $\left(6-9^{\circ} \mathrm{C} ; 70 \% \mathrm{UR}\right)$ e mantidas, por 24 horas, em condições ambientais, antes da determinação do teor de água e realização dos testes de germinação.
As sementes de ambas as espécies tiveram seu teor de água determinado pelo método de estufa a $103 \pm$ $2^{\circ} \mathrm{C}$, por 17 horas (BRASIL, 1992), com quatro repetições de 1 grama de sementes por lote.

\section{Primeira etapa}

Foram utilizados lotes de sementes de ipê-roxo colhidos em diversas matrizes, em Lavras, MG, nos anos de 1999 e 2000. As sementes foram colhidas no início do processo de deiscência dos frutos, beneficiadas manualmente e mantidas em galpão, à sombra, para secagem natural por 5 dias. Os lotes foram armazenados em sacos de polietileno, em câmara fria, por 14 meses (lote 1999) e 2 meses (lote 2000).

Para a seleção das temperaturas para a germinação de sementes de ipê-roxo, foi realizado um primeiro experimento instalado em mesa de termogradiente, com temperaturas variando de $20,9^{\circ} \mathrm{C}$ a $34,4^{\circ} \mathrm{C}$, sob luz branca constante. Foram utilizadas cinco repetições de 20 sementes, em delineamento inteiramente casualizado, para cada lote e temperatura. As sementes foram desinfestadas com solução de hipoclorito de sódio $2 \%$ por 2 minutos, lavadas em água destilada e colocadas para germinar sobre papel umedecido com água, na proporção 2,5 vezes o peso seco do papel, em gerbox.

Em um segundo experimento, realizado três meses após o primeiro, as sementes foram desinfestadas, como citado anteriormente e submetidas à germinação em BODs, sob luz constante e temperaturas de $25^{\circ} \mathrm{C}, 30^{\circ} \mathrm{C}$ e $35^{\circ} \mathrm{C}$. A semeadura foi realizada sobre substrato de areia, em bandejas, em delineamento inteiramente casualizado, contendo cinco repetições de 20 sementes cada uma.

\section{Segunda etapa}

As sementes de ipê-roxo e ipê-amarelo foram colhidas, beneficiadas e armazenadas como citado na primeira etapa. Para o ipê-roxo, foram utilizados lotes colhidos em Lavras, MG, nos anos de 2000 e 2001 e armazenados por 14 e 2 meses, respectivamente. Os lotes de ipê-amarelo foram colhidos em Ribeirão Vermelho, MG, no ano de 1998 (1998RV); Lavras, MG, no ano de 2000 (2000Lavras) e Belo Horizonte, MG, no ano de 2000 (2000BH) e armazenados por 26 meses, para o lote 1998RV e 2 meses, para os lotes 2000Lavras e 2000BH.

Os tratamentos consistiram de três regimes de luz: luz branca contínua com temperatura de $30^{\circ} \mathrm{C}$; luz branca alternada com fotoperíodo de 8 horas à 
temperatura de $20^{\circ} \mathrm{C} / 30^{\circ} \mathrm{C}$ e escuro contínuo à temperatura de $30^{\circ} \mathrm{C}$. As sementes foram mantidas em câmara de germinação tipo BOD, em gerbox, sobre substrato areia. No tratamento escuro, os gerbox foram colocados em dois sacos de polietileno pretos. Os experimentos foram realizados em delineamento inteiramente casualizado, com 5 repetições de 20 sementes para cada regime de luz e lote. As sementes foram desinfestadas com hipoclorito de sódio e avaliadas conforme as Regras para Análise de Sementes (BRASIL, 1992). A primeira avaliação do tratamento escuro foi realizada sob luz verde.

Nas duas etapas, foram avaliadas plântulas normais e anormais, sementes mortas, duras e dormentes, segundo as Regras para Análise de Sementes (BRASIL, 1992), aos 14 dias - primeira contagem e aos 28 dias após a semeadura - contagem final (MACHADO, 1999).

Os dados de germinação obtidos nas duas etapas foram transformados em arc sen. $\sqrt{ } \mathrm{x} / 100$ e submetidos à análise de variância. As médias dos tratamentos foram comparadas pelo teste de Tukey, usando o programa SANEST (ZONTA et al., 1985).

\section{RESULTADOS E DISCUSSÃO}

\section{Primeira etapa}

As sementes de ipê-roxo dos lotes 1999 e 2000, utilizadas para o estudo da temperatura ideal de germinação, estavam com teor de água em torno de $40 \%$, por ocasião da colheita e $7,5 \%$ e $8 \%$ por ocasião da realização dos testes, respectivamente. O teor de água no qual as sementes entram em equilíbrio com o ambiente depende, além da temperatura e umidade relativa, da espessura e composição química das sementes (JUSTICE \& BASS, 1978). A composição química de sementes do gênero Tabebuia varia conforme a espécie, como em ipê-amarelo ( $T$. serratifolia), que possui sementes oleaginosas (FREITAS et al., 1979) e ipê-branco (T. roseo-alba), com sementes protéicas (DEGAN et al., 1997).

No primeiro experimento, com utilização da mesa termogradiente, a faixa de temperatura de $24,5^{\circ} \mathrm{C}$ a $34,4^{\circ} \mathrm{C}$, de modo geral, proporcionou resultados numéricos superiores de germinação das sementes de ipê-roxo de ambos os lotes, em comparação com temperaturas mais baixas (Tabela 1). A germinação máxima conseguida no estudo foi de $43 \%$ para o lote 2000 e 15\% para o lote 1999, evidenciando a baixa qualidade dos lotes, o que foi confirmado pelos resultados obtidos no experimento na segunda etapa, com germinação realizada em BOD (Tabela 2).

Quando o teste de germinação foi instalado em BODs, observou-se que somente a temperatura de $30^{\circ} \mathrm{C}$ favoreceu a germinação das sementes do lote 2000, o que foi constatado tanto na primeira contagem como na contagem final de germinação (Tabela 2). As sementes do lote 1999 não germinaram, sendo, ao final do teste, observados $100 \%$ de sementes mortas em todas as temperaturas testadas.

As diferenças de germinação encontradas entre os dois experimentos referem-se, provavelmente, à utilização de diferentes substratos e à maior deterioração das sementes no armazenamento a que foram submetidas durante o intervalo da realização dos experimentos, sendo mais prejudicial ao lote de qualidade inferior. Segundo Carvalho \& Nakagawa (2000), dependendo da qualidade do lote, as sementes apresentam comportamentos diferentes durante o armazenamento.

TABELA 1 - Porcentagens de plântulas normais de Tabebuia impetiginosa obtidas na primeira contagem e contagem final do teste de germinação em mesa termogradiente, para os diferentes lotes utilizados.

\begin{tabular}{ccccc}
\hline & \multicolumn{2}{c}{ Primeira contagem (\%) } & \multicolumn{2}{c}{ Contagem final (\%) } \\
\cline { 2 - 5 } Temperatura $\left({ }^{\circ} \mathbf{C}\right)$ & $\mathbf{2 0 0 0}$ & $\mathbf{1 9 9 9}$ & $\mathbf{2 0 0 0}$ & $\mathbf{1 9 9 9}$ \\
\hline 20,9 & $12 \mathrm{~A} \mathrm{~b}$ & $0 \mathrm{~B} \mathrm{~b}$ & $20 \mathrm{~A} \mathrm{~b}$ & $2 \mathrm{~B} \mathrm{~b}$ \\
22,5 & $14 \mathrm{~A} \mathrm{~b}$ & $1 \mathrm{~B} \mathrm{~b}$ & $23 \mathrm{~A} \mathrm{~b}$ & $2 \mathrm{~B} \mathrm{~b}$ \\
24,5 & $28 \mathrm{~A} \mathrm{ab}$ & $6 \mathrm{~B} \mathrm{ab}$ & $35 \mathrm{~A} \mathrm{ab}$ & $8 \mathrm{~B} \mathrm{ab}$ \\
30,2 & $37 \mathrm{~A} \mathrm{a}$ & $13 \mathrm{~B} \mathrm{a}$ & $43 \mathrm{~A} \mathrm{a}$ & $15 \mathrm{~B} \mathrm{a}$ \\
34,4 & $26 \mathrm{~A} \mathrm{ab}$ & $9 \mathrm{~B} \mathrm{a}$ & $26 \mathrm{~A} \mathrm{~b}$ & $15 \mathrm{~A} \mathrm{a}$ \\
\hline
\end{tabular}

Médias seguidas pela mesma letra minúscula nas colunas e maiúsculas nas linhas, em cada contagem separadamente, não diferem entre si, pelo Teste de Tukey a 5\%.

Ciênc. agrotec., Lavras, v. 29, n. 3, p. 642-648, maio, jun., 2005 
TABELA 2 - Porcentagens de plântulas normais de Tabebuia impetiginosa obtidas na primeira contagem e contagem final do teste de germinação em BOD.

\begin{tabular}{ccccc}
\hline & \multicolumn{2}{c}{ Primeira contagem (\%) } & \multicolumn{2}{c}{ Contagem final (\%) } \\
\cline { 2 - 5 } Temperatura $\left({ }^{\circ} \mathbf{C}\right)$ & \multicolumn{2}{c}{ Lotes } & $\mathbf{2 0 0 0}$ & $\mathbf{1 9 9 9}$ \\
\hline 25 & $0 \mathrm{2000}$ & $\mathbf{1 9 9 9}$ & $13 \mathrm{~A} \mathrm{~b}$ & $0 \mathrm{~B} \mathrm{a}$ \\
30 & $40 \mathrm{~A} \mathrm{a}$ & $0 \mathrm{~B} \mathrm{a}$ & $51 \mathrm{~A} \mathrm{a}$ & $0 \mathrm{~B} \mathrm{a}$ \\
35 & $2 \mathrm{~A} \mathrm{~b}$ & $0 \mathrm{~A} \mathrm{a}$ & $6 \mathrm{~A} \mathrm{~b}$ & $0 \mathrm{~B} \mathrm{a}$ \\
\hline
\end{tabular}

Médias seguidas pela mesma letra minúscula nas colunas e maiúsculas nas linhas, em cada contagem separadamente, não diferem entre si pelo Teste de Tukey a 5\%.

A temperatura de $35^{\circ} \mathrm{C}$ pode ter sido drástica para a germinação de sementes de ipê-roxo, impedindo o desenvolvimento do embrião. $\mathrm{O}$ efeito de temperaturas altas, restritivas à germinação, é explicado por possíveis alterações enzimáticas, pela condição fisiológica da semente ou pela insolubilidade do oxigênio nessas condições, aumentando sua exigência e acelerando a velocidade respiratória das sementes (MARCOS FILHO, 1986; POPINIGIS, 1985).

A temperatura de $30^{\circ} \mathrm{C}$ foi utilizada no teste de germinação de espécies do gênero Tabebuia, como $T$. chrysotricha (CARVALHO et al., 1976), T. vellosoi (FIGLIOLIA et al., 1988) e T. cassinoides (RAMOS \& BIANCHETTI, 1984). Já em trabalhos realizados com $T$. impetiginosa, foram empregadas as temperaturas de $20^{\circ} \mathrm{C}$ $30^{\circ} \mathrm{C}$ (CUNHA et al., 1992; MAEDA \& MATTHES, 1984; MELLO \& EIRA, 1995), e $25^{\circ} \mathrm{C}$ (BARBOSA, 1982; MELLO \& EIRA, 1995; PINTO et al., 1986).

\section{Segunda etapa}

Por ocasião da realização dos testes de germinação da segunda etapa, as sementes dos lotes 2000 e 2001 de ipê-roxo estavam com $8,0 \%$ e $8,3 \%$ de umidade, respectivamente, e as sementes dos lotes de ipê-amarelo 1998RV, 2000Lavras e 2000BH, com 9,3\%, $7,1 \%$ e $7,3 \%$, respectivamente. Por ocasião da colheita, as sementes estavam com umidade em torno de $40 \%$.

No estudo do efeito da luz sobre a germinação de sementes de ipê-roxo foi observado que tanto o tratamento luz constante como escuro foram eficientes em propiciar a germinação das sementes por ocasião da primeira contagem, para ambos os lotes. Já para os resultados da contagem final, a germinação sob luz constante foi superior aos resultados de germinação sob alternância de luz ou escuro para o lote 2001, não havendo diferenças significativas no lote 2000, apesar de apresentar maiores valores absolutos de germinação sob luz constante (Tabela 3 ).

De modo geral, as sementes de ipê-roxo, independente do ano de colheita e do regime de luz utilizado no teste, apresentaram tendências ou valores máximos de germinação em temperatura de $30^{\circ} \mathrm{C}$. Dessa forma, temperatura de $30^{\circ} \mathrm{C}$ parece ser a mais adequada para ser utilizada em testes de germinação de sementes de ipê-roxo, propiciando valores máximos de germinação, independente das condições fisiológicas e edafoclimáticas durante sua formação.

Para sementes de ipê-amarelo, a superioridade do tratamento luz constante pôde ser observada tanto na primeira contagem de germinação, como na contagem final, para todos os lotes, exceto para 2000BH, que não diferiu estatisticamente do tratamento de alternância de luz (Tabela 4). Segundo Malavasi (1988), o nível de deterioração e a procedência do lote são fatores que influenciam a sensibilidade à luz durante a germinação.

Apesar de não terem sido observadas diferenças significativas para alguns lotes, entre tratamentos de luz, houve uma tendência de melhores resultados de germinação de sementes de ipê na presença de luz constante.

A germinação das sementes em relação à luz é uma resposta ecofisiológica da espécie, que está correlacionada com o seu posicionamento no estádio sucessional da floresta. Kageyama \& Márquez (1981) classificaram as espécies T. impetiginosa e $T$. serratifolia como pioneiras, ou seja, espécies que possuem sementes que exigem condições de luminosidade para germinar (PIÑA-RODRIGUES et al., 1990). Amaral et al. (1992) observaram que a porcentagem de estabelecimento de plântulas de $T$. serratifolia foi três vezes maior na condição de clareira, salientando que, provavelmente, as sementes dessa espécie necessitam de luz para a germinação. 
OLIVEIRA, L. M. de et al.

TABELA 3 - Porcentagens de plântulas normais de Tabebuia impetiginosa obtidas na primeira contagem e contagem final do teste de germinação.

\begin{tabular}{lcccc}
\hline & \multicolumn{2}{c}{ Primeira contagem (\%) } & \multicolumn{2}{c}{ Contagem final (\%) } \\
\cline { 2 - 5 } \multicolumn{1}{c}{ Tratamentos } & \multicolumn{2}{c}{ Lotes } & \multicolumn{2}{c}{ Lotes } \\
& $\mathbf{2 0 0 1}$ & $\mathbf{2 0 0 0}$ & $\mathbf{2 0 0 1}$ & $\mathbf{2 0 0 0}$ \\
\hline Luz constante $\left(30^{\circ} \mathrm{C}\right)$ & $24 \mathrm{~A} \mathrm{a}$ & $15 \mathrm{~A} \mathrm{a}$ & $81 \mathrm{~A} \mathrm{a}$ & $58 \mathrm{~B} \mathrm{a}$ \\
Alternância de luz $\left(20^{\circ} \mathrm{C} / 30^{\circ} \mathrm{C}\right)$ & $0 \mathrm{~A} \mathrm{~b}$ & $0 \mathrm{~A} \mathrm{~b}$ & $41 \mathrm{~A} \mathrm{~b}$ & $39 \mathrm{~A} \mathrm{a}$ \\
Escuro $\left(30^{\circ} \mathrm{C}\right)$ & $20 \mathrm{~A} \mathrm{a}$ & $13 \mathrm{~A} \mathrm{a}$ & $49 \mathrm{~A} \mathrm{~b}$ & $46 \mathrm{~A} \mathrm{a}$ \\
\hline $\begin{array}{l}\text { Médias seguidas pela mesma } \\
\text { separadamente, não diferem entre si, pelo Teste de Tukey a } 5 \% .\end{array}$
\end{tabular}

TABELA 4 - Porcentagens de plântulas normais de Tabebuia serratifolia obtidas na primeira contagem e contagem final do teste de germinação.

\begin{tabular}{ccccccc}
\hline \multirow{2}{*}{ Tratamentos } & \multicolumn{3}{c}{ Primeira contagem (\%) } & \multicolumn{3}{c}{ Contagem final (\%) } \\
\cline { 2 - 6 } & 1998RV & $\begin{array}{c}\text { Lotes } \\
\text { 2000Lavras }\end{array}$ & 2000BH & 1998RV & Lotes \\
\hline $\begin{array}{c}\text { Luz constante } \\
\text { (30oC) }\end{array}$ & $17 \mathrm{~B} \mathrm{a}$ & $48 \mathrm{~A} \mathrm{a}$ & $22 \mathrm{~B} \mathrm{a}$ & $54 \mathrm{~B} \mathrm{a}$ & $89 \mathrm{~A} \mathrm{a}$ & $54 \mathrm{~B} \mathrm{a}$ \\
$\begin{array}{c}\text { Alternância de luz } \\
\text { (20-30oC) } \\
\begin{array}{c}\text { Escuro } \\
\text { (30oC) }\end{array}\end{array}$ & $0 \mathrm{~B} \mathrm{~b}$ & $14 \mathrm{~A} \mathrm{~b}$ & $9 \mathrm{AB} \mathrm{b}$ & $34 \mathrm{~B} \mathrm{~b}$ & $62 \mathrm{~A} \mathrm{~b}$ & $46 \mathrm{~B} \mathrm{a}$ \\
\hline
\end{tabular}

Médias seguidas pela mesma letra minúscula nas colunas
separadamente, não diferem entre si, pelo Teste de Tukey a 5\%.

Vale ressaltar que durante os testes de germinação da primeira e segunda etapas foi observada a presença do fungo Alternaria alternata que, segundo Sales \& Castro (1994), pode afetar o desenvolvimento de plântulas de $T$. serratifolia.

\section{CONCLUSÃO}

A temperatura de $30^{\circ} \mathrm{C}$ foi adequada para a germinação de sementes de ipê-roxo, independente do ano de colheita ou da qualidade fisiológica dos lotes, enquanto a resposta da germinação em relação ao regime de luz variou conforme o ano de colheita.

A condição ideal para realização do teste de germinação em sementes de ipê-amarelo, independente da procedência e do ano de colheita, foi sob luz constante a $30^{\circ} \mathrm{C}$.

\section{REFERÊNCIAS BIBLIOGRÁFICAS}

AMARAL, W. A. N.; BORGES, K. H.; MELO, S. L. M. Frutificação, predação de sementes e estabelecimento de plântulas de Tabebuia serratifolia Nichols. In: CONGRESSO NACIONAL SOBRE ESSÊNCIAS NATIVAS, 2., 1992. Anais... [S.l.: s.n.], 1992. p. 298-302.

BARBOSA, J. M. Germinação de sementes de sete essências nativas. Silvicultura em São Paulo, São Paulo, v. 16-A, pt. 1, p. 322-327, 1982.

BRASIL. Ministério da Agricultura. Regras para análise de sementes. Brasília, 1992. 365 p. 
CARVALHO, N. M.; GOES, M. de; AGUIAR, I. B.; FERNANDES, P. D. Armazenamento de sementes de ipê-amarelo (Tabebuia chrysotricha). Científica, Botucatu, v. 4, n. 3, p. 315-319, 1976.

CARVALHO, P. E. R. Espécies florestais brasileiras: recomendações silviculturais, potencialidades e uso da madeira. Colombo: EMBRAPA/CNPF, 1994. 640 p.

CARVALHO, N. M.; NAKAGAWA, J. Sementes: ciência, tecnologia e produção. Jaboticabal: FUNEP, 2000. 588 p.

CUNHA, R.; SALOMÃO, A. N.; EIRA, M. T. S.; MELLO, C. M. C. de; TANAKA, D. M. Métodos para conservação a longo prazo de sementes de Tabebuia spp.: Bignoniaceae. Revista do Instituto Florestal, São Paulo, v. 4, n. 4, p. 675-678, mar. 1992.

DEGAN, P.; AGUIAR, I. B.; SADER, R.; PINTO, L. R. Composição química, sanidade, secagem e germinação de sementes de ipê-branco (Tabebuia roseo-alba (Ridl.) Sand. - Bignoniaceae). Revista Brasileira de Horticultura Ornamental, Campinas, v. 3, n. 1, p. 41-47, 1997.

DIAS, L. A. S.; KAGEYAMA, P. Y.; ISSIKI, K. Qualidade de luz e germinação de sementes de espécies arbóreas tropicais. Acta Amazônica, Manaus, v. 22, n. 1, p. 79-84, jan./mar. 1992.

FIGLIOLIA, M. B.; SILVA, A.; JARDIM, D. C. P.; IWANE, M. S. S. Viabilidade de sementes liofilizadas de essências florestais nativas. Silvicultura em São Paulo, São Paulo, v. 20/22, p. 47-55, 1988.

FREITAS, S. C.; CANDIDO, J. F.; CONDE, A. R.; HARA, T. Determinação de equilíbrio higroscópico e viabilidade de sementes de ipê-amarelo Tabebuia serratifolia (Vahl) Nichols) armazenadas em diferentes umidades relativas. Revista Árvore, Viçosa, v. 3, n. 2, p. 135-144, jul./dez. 1979.

JUSTICE, O. L.; BASS, L. N. Principles and practices of seed storage: agriculture handbook. Washington: [s.n.], 1978. 289 p.

KAGEYAMA, P. Y.; MARQUEZ, F. C. M. Comportamento de espécies de curta longevidade armazenadas com diferentes teores de umidade inicial (gênero Tabebuia). Piracicaba: IEF, 1981. 4 p. (Circular técnico, 26).
MACHADO, C. F. Metodologia para a condução do teste de germinação em sementes de ipê-amarelo (Tabebuia serratifolia (Vahl) Nicholson Bignoniaceae). 1999. 19 f. Monografia (Graduação) Universidade Federal de Lavras, Lavras, 1999.

MAEDA, J. A.; MATTHES, L. A. F. Conservação de sementes de ipê. Bragantia, Campinas, v. 43, n. 1, p. 45-50, 1984.

MALAVASI, M. M. Germinação de sementes. In: PIÑA RODRIGUES, F. C. M. Manual de análise de sementes florestais. Campinas: Fundação Cargill, 1988. p. 25-40.

MARCOS FILHO, J. Germinação de sementes. In: FUNDACAO CARGILL. Atualização em produção de sementes. Campinas, 1986. 223 p.

MELLO, C. M. C. de; EIRA, M. T. S. de. Conservação de sementes de ipês (Tabebuia spp.). Revista Árvore, Viçosa, v. 19, n. 4, p. 427-432, out./dez. 1995.

PIÑA-RODRIGUES, F. C. M.; COSTA, L. G. S.; REIS, A. Estratégias de estabelecimento de espécies arbóreas e o manejo de florestas tropicais. In: CONGRESSO FLORESTAL BRASILEIRO, 6., 1990, Campos de Jordão. Anais... Campos de Jordão: [s.n.], 1990. p. 677-684.

PINTO, M. M.; SADER, R.; BARBOSA, J. M. Influência do tempo de secagem e do armazenamento sobre a viabilidade das sementes de ipê-rosa. Revista Brasileira de Sementes, Brasília, v. 1, n. 1, p. 37-47, 1986.

POPINIGIS, F. Fisiologia da semente. Brasília: AGIPLAN, 1985. 289 p.

RAMOS, A.; BIANCHETTI, A. Influência da temperatura e substrato na germinação de sementes florestais. In: SIMPÓSIO INTERNACIONAL DE MÉTODOS DE PRODUÇÃO DE QUALIDADE DE SEMENTES E MUDAS FLORESTAIS, 1984, Curitiba. Anais... Curitiba: UFPA, 1984. p. 193-204.

SALES, N. L. P.; CASTRO, H. A. Efeito da população fúngica sobre a germinação das sementes e o desenvolvimento inicial de plântulas de ipê-amarelo (Tabebuia serratifolia (Vahl.) Nich. e barbartimão (Stryphnodendron adstringens (Mart.) Couville). Ciência e Pratica, Lavras, v. 18, n. 1, p. 83-89, jan./mar. 1994. 
SALOMÃO, A. N.; MUNDIN, R. C. Efeito de diferentes graus de umidade na viabilidade de sementes de 11 espécies arbóreas durante a criopreservação. Informativo ABRATES, [S.l.], v. 7, n. 1/2, p. 224, jul./ago. 1997.

SIQUEIRA, A. C. M. F.; NOGUEIRA, J. C. B. Essências brasileiras e sua conservação genética no Instituto Florestal de São Paulo. In: CONGRESSO NACIONAL SOBRE ESSÊNCIAS NATIVAS, 1992,
São Paulo. Anais... Revista do Instituto Florestal, São Paulo, v. 4, n. 4, p. 1187, mar. 1992. Edição especial.

ZONTA, E. F.; MACHADO, A. A.; SILVEIRA JÚNIOR, P. Sistema de análise estatística (SANEST) para microcomputador (versão 1. 0). In: SIMPÓSIO DE ESTATÍSTICA APLICADA À EXPERIMENTAÇÃO AGRONÔMICA, 1985, Piracicaba. Anais... Piracicaba: ESALQ, 1985. p. 74-90. 